\title{
The influence of vitamin $D$ deficiency on eradication rates of Helicobacter pylori
}

\author{
Oguzhan Yildirim ${ }^{1, A, C-F}$, Tulay Yildirim" ${ }^{2, B-D, F}$, Yuksel Seckin ${ }^{1, B, D, E}$, Pelin Osanmaz ${ }^{3, B, C}$, Yilmaz Bilgic ${ }^{1, B, D}$, Rafet Mete Met $^{4, B, D}$ D-F \\ ${ }^{1}$ Department of Gastroenterology, Faculty of Medicine, Inonu University, Malatya, Turkey \\ 2 Department of Physiotherapy and Rehabilitation, Faculty of Medicine, Inonu University, Malatya, Turkey \\ ${ }^{3}$ Department of Internal Medicine, Faculty of Medicine, Namik Kemal University, Tekirdag, Turkey \\ ${ }^{4}$ Department of Gastroenterology, Faculty of Medicine, Namik Kemal University, Tekirdag, Turkey \\ A - research concept and design; $\mathrm{B}$ - collection and/or assembly of data; $\mathrm{C}$ - data analysis and interpretation; \\ $D$ - writing the article; $E$ - critical revision of the article; $F$ - final approval of the article
}

\section{Address for correspondence}

Oguzhan Yildirim

E-mail:droguzhanyildirim@hotmail.com

Funding sources

None declared

Conflict of interest

None declared

Received on March 26, 2016

Reviewed on June 2, 2016

Accepted on September 29, 2016

\section{Abstract}

Background. Helicobacter pylori eradication therapy improves the healing of various gastro-duodenal diseases such as chronic gastritis and peptic ulcer, and also reduces gastric cancer incidence. Several studies have reported on risk factors other than antibiotic resistance related to Helicobacter pylori eradication failure.

Objectives. In this study, we aimed to investigate whether or not the serum levels of 25-hydroxy-vita$\min \mathrm{D}(25(\mathrm{OH}) \mathrm{D})$ influence eradication rates of H.pylori.

Material and methods. 220 patients diagnosed with H.pylori gastritis using endoscopic biopsy had their $25-\mathrm{OH}$ vitamin $\mathrm{D}$ levels measured via the electrochemiluminescence method before beginning eradication therapy of H.pylori. Gastric biopsies obtained at endoscopy were examined for H.pyloristrains and histopathologic findings. All patients were treated with bismuth-containing quadruple therapy for 14 days. H.pylori eradication was determined via the 14C-urea breath test performed 4 weeks after the end of therapy. Based on the $25-0 \mathrm{H}$ vitamin D levels, the patients were divided into 2 groups: group 1 (deficient) had a vitamin D level of $<10 \mathrm{ng} / \mathrm{mL}$, while group 2 (sufficient) had a vitamin D level of $\geq 10 \mathrm{ng} / \mathrm{mL}$.

Results. Eradication was successful in 170 (77.2\%) patients and failed in 50 (22.7\%) patients. The prevalence of 25(OH)D deficiency was 30.5\%. Mean 25(OH)D levels were significantly lower in the eradication failure group compared to the successful treatment group $(9.13 \pm 4.7$ vs $19.03 \pm 8.13 ; p=0.001)$. There were significantly more patients with deficient $25(\mathrm{OH}) \mathrm{D}$ levels in the failed treatment group compared to the successful treatment group ( $p=0.001)$.

Conclusions. Our findings suggest that 25-OH vitamin D deficiency may be considered a risk factor related to eradication failure of $H$.pylori, which may lead to a need for supplementation of vitamin D before eradication of H.pylori.

Key words: vitamin D, Helicobacter pylori, Helicobacter pylori eradication

DOI

10.17219/acem/65430

\section{Copyright}

Copyright by Author(s)

This is an article distributed under the terms of the

Creative Commons Attribution Non-Commercial License

(http://creativecommons.org/licenses/by-nc-nd/4.0/) 


\section{Introduction}

Helicobacter pylori (H.pylori) is a gram-negative bacterium that colonizes the human stomach; it is also increasingly prevalent, ranging from $25 \%$ in developed countries to $90 \%$ in developing countries. ${ }^{1}$ H.pylori is a main causative factor in various gastrointestinal diseases such as chronic gastritis, peptic ulcers, mucosa-associated lymphoid tissue lymphoma (MALT) and gastric cancer. ${ }^{2}$ H.pylori eradication significantly affects the treatment of both peptic ulcers and gastric lymphoma. ${ }^{3}$ Therefore, successful eradication of H.pylori infection may prevent the development of gastric cancer. Clearly, it is important to eradicate this bacterium and its related risk factors. ${ }^{4}$ Bacterial and host factors in H.pylori eradication therapy include antibiotic resistance, virulence factors and host-related genetic disorders (CYP2C19, IL-1B, multidrug-resistant transporter-1). ${ }^{5}$ Host immunity also plays an important role against an infectious disease such as H.pylori infection. Meanwhile, vitamin D is responsible for regulating calcium and phosphorus metabolism, both of which are needed for bone formation. Beyond its wellknown role in bone formation, vitamin D also has an immunomodulator role in targeting various immune cells, including monocytes, macrophages and dendritic cells, as well as T-lymphocytes and B-lymphocytes. ${ }^{6}$ Hence, vitamin D deficiency may increase the incidence of immune system disorders and may be a risk factor for the progression of an infectious disease.

Vitamin D deficiency might increase the risk of H.pylori infection, yet this association has yet to be evaluated. Therefore, in this study, we aimed to evaluate the association between vitamin D deficiency and the treatment of H.pylori infection.

\section{Material and methods}

\section{Patients}

Patients complaining of dyspeptic symptoms for at least 1 month underwent diagnostic esophago-gastro-duodenoscopy. All patients were non-ulcer dyspeptic patients. The study included 220 sequential patients diagnosed with H.pylori gastritis by endoscopic biopsy for prospective observation in a gastroenterology clinic between September 2014 and December 2015. The research excluded patients who had previously received H.pylori eradication treatment, vitamin D supplements, corticosteroids/immuno-suppressive treatment, antibiotics, or anti-inflammatory or acid suppressive treatment in the prior 2 months. It also excluded those with a history of systemic inflammatory or autoimmune disorders, gastric surgery, renal failure, liver cirrhosis, and malignancies. The study was planned according to the ethics guidelines of the Helsinki Declaration, informed consent was obtained from all the participants, and the research was approved by our hospital's Institutional Research Ethics Board.

\section{Endoscopic evaluation}

Endoscopy was conducted with Olympus Evis Exera 160 videoendoscopes (Olympus America Inc., Center Valley, USA). Two biopsy specimens were obtained from the antrum and 2 from the corpus for histological examination.

\section{Histopathologic examination}

The biopsy samples were fixed in $10 \%$ formalin before being sliced into 4-6 $\mathrm{mm}$ pieces, dehydrated in ethanol, embedded in paraffin wax, sectioned ( $5 \mu \mathrm{m}$ thick), and stained with hematoxylin and eosin (H\&E) for histological examination and Giemsa stain for H.pylori identification. A blinded histopathologist examined all specimens and diagnosed cases as active or chronic gastritis. The updated Sydney system was used to grade the activity of gastritis, inflammation, atrophy and H.pylori density. ${ }^{8}$ Thus, mucosal atrophy was defined by the loss of glandular tissue; inflammation of gastric mucosa was defined by the presence of an inflammatory infiltrate composed of lymphocytes and plasma cells; and activity of gastric mucosa was defined by the presence of neutrophil cells at superficial or deep layers. The degree of activity, inflammation, atrophy and H.pylori density were classified into 4 categories, scored on a scale of $0-3(0=$ none; 1 = mild; 2 = moderate; 3 = severe).

\section{Treatment protocol}

All infected patients were treated for 14 days with bismuth-containing quadruple eradication therapy consisting of colloidal bismuth sub-citrate $300 \mathrm{mg}$ q.i.d., pantaprazole $40 \mathrm{mg}$ b.i.d., tetracycline $500 \mathrm{mg}$ q.i.d., and metronidazole $500 \mathrm{mg}$ t.i.d.

\section{Confirmation of Helicobacter pylori eradication (14C-urea breath test)}

A 14C-urea breath test was performed at least 4 weeks after treatment completion. Following overnight fasting, patients used $25 \mathrm{~mL}$ of water to swallow $37 \mathrm{kBq}(1 \mathrm{mCi})$ of an encapsulated form of 14C-urea/citric acid composition (Helicap, Noster System AB, Stockholm, Sweden). Breath samples of the patients were collected with a special dry cartridge system (Heliprobe BreathCard, Noster System AB) at $10 \mathrm{~min}$. Patients exhaled gently into the cartridge mouthpiece until the indicator membrane changed color from orange to yellow. The breath-card was inserted into a special small desktop Geiger-Muller counter (Heliprobe analyzer, Noster System AB), and activity was counted for $250 \mathrm{~s}$. The results were expressed both as counts per minute (HCPM) and as a grade 
(0 - not infected, CPM < 25; 1 - equivocal, CPM 25-50; 2 - infected, CPM > 50). This procedure adhered to manufacturer guidelines regarding the counts obtained from the cartridges, and a negative test result was defined as H.pylori eradication.

\section{Laboratory measurements}

Patients who had the histopathological diagnosis of H.pylori infection underwent the assessment of serum 25-hydroxyvitamin D3 levels and CagA seropositivity before H.pylori treatment. Serum 25(OH)D3 levels were measured using an electrochemiluminescence method (Roche Diagnostics GmBH, Mannheim, Germany), with inter-assay and intra-assay coefficients of variation (CVs) of $2.4 \%$ and $5.7 \%$, respectively. Sera obtained by centrifugation were stored at $-20^{\circ} \mathrm{C}$ and analyzed simultaneously by technicians who were blind to group allocation. Serologic assays for specific IgG antibodies against CagA protein were analyzed by enzyme immunoassays (DIA.PRO Diagnostic Bioprobes S.r.l, Milan, Italy). CagA antibody titers $(\geq 8 \mathrm{U} / \mathrm{mL})$ were classified as positive, per manufacturer instructions. Vitamin D deficiency was defined as a condition in which the $25(\mathrm{OH}) \mathrm{D}$ serum level was lower than $10 \mathrm{ng} / \mathrm{mL} .{ }^{9} \mathrm{Be}-$ fore beginning H.pylori treatment patients were divided into 2 groups as follows: group 1 (vitamin D deficient) had a vitamin D level of $<10 \mathrm{ng} / \mathrm{mL}$, and group 2 (vitamin $D$ sufficient) had a vitamin D level of $\geq 10 \mathrm{ng} / \mathrm{mL}$.

\section{Statistical analysis}

SPSS for Windows v. 17.0 was used for the statistical analyses of our study data. Mean standard deviations (SD) were used to identify the data related to the continuous variables, and categorical variables were provided as percentages. The Kolmogorov-Smirnov normalizing test was used to determine whether the continuous variable data fit a normal distribution. The comparison of the variables with normal distribution was tested with an unpaired t-test, and the comparison of the variables without normal distribution was tested with a Mann-Whitney U test. The categorical variables were compared with Pearson's $\mathrm{X}^{2}$ test, and a $\mathrm{p}$-value $<0.05$ was considered statistically significant.

\section{Results}

The study involved 220 patients. In 170 (77.2\%) patients, H.pylori was eradicated successfully, while in 50 (22.7\%) patients, eradication failed. At the end of therapy, all patients' compliance with the drug protocol was excellent. There were no significant differences between the eradication successful and eradication failure groups regarding age or sex ( $\mathrm{p}=0.54$ and $\mathrm{p}=0.44$, respectively) (Table 1$)$. We evaluated the relationship of histopathologic findings and eradication rates between the eradication successful and eradication failure groups. In the successful treatment group, the degree of activity and inflammation were significantly higher than that in the failed treatment group (both values of $\mathrm{p}=0.001)$. However, no significant differences were seen between the 2 eradication groups in terms of the degree of atrophy and H.pylori density (both had values of $\mathrm{p}>0.05$ ) (Table 2). The H.pylori virulence marker CagA was positive in 108 (63.5\%) patients in the successful treatment group, and it was positive in $8(16 \%)$ patients in the failure treatment group. We found CagA-positive strains to have significantly higher eradication rates compared to negative ones ( $\mathrm{p}=0.001$ ) (Table 2). We divided patients into 2 groups according to vitamin $25(\mathrm{OH}) \mathrm{D}$ status; mean vitamin 25(OH)D levels were significantly lower in the eradication failure group compared to the successful treatment group ( $9.13 \pm 4.7$ vs $19.03 \pm 8.13$; $\mathrm{p}=0.00)$ (Table 1). In addition, all patients had an overall $30.5 \%$ vitamin $25(\mathrm{OH}) \mathrm{D}$ deficiency. We found $42(84 \%)$ patients in the failed treatment group and $25(14.7 \%)$ patients in the successful treatment group to be vitamin $25(\mathrm{OH}) \mathrm{D}$ deficient. As shown in Fig. 1, vitamin 25(OH)D deficiency was significantly higher in the failed treatment group compared to the successful treatment group $(\mathrm{p}=0.001)$.

\section{Discussion}

In this study, we found H.pylori eradication rates to be significantly lower in patients with low vitamin D levels. Bacterial and host-related risk factors such as antibiotic resistance, virulence factors and host-related genetic disorders are associated with H.pylori eradication failure. ${ }^{5}$

Table 1. Demographic and vitamin 25(OH)D level differences between the successful and failed eradication groups of H.pylori

\begin{tabular}{|l|c|c|c|}
\hline \multicolumn{1}{|c|}{ Variable } & $\begin{array}{c}\text { Failure } \\
(\mathrm{n}=50)\end{array}$ & $\begin{array}{c}\text { Successful } \\
(\mathrm{n}=170)\end{array}$ & p-value \\
\hline Age $($ mean $\pm \mathrm{SD})$ & $47.3 \pm 14.3$ & $47.5 \pm 13.9$ & 0.546 \\
\hline Male $(\mathrm{n}, \%)$ & $27(54 \%)$ & $102(60 \%)$ & 0.449 \\
\hline Vitamin 25(OH)D (mean $\pm \mathrm{SD})$ & $19.0 \pm 8.1$ & $9.1 \pm 4.7$ & 0.001 \\
\hline
\end{tabular}

Table 2. Histological scores and CagA seropositivity between the successful treatment group and the failed H.pylori eradication group (mean \pm SD)

\begin{tabular}{|l|c|c|c|}
\hline \multicolumn{1}{|c|}{ Variable } & $\begin{array}{c}\text { Failure } \\
(\mathrm{n}=50)\end{array}$ & $\begin{array}{c}\text { Successful } \\
(\mathrm{n}=170)\end{array}$ & p-value \\
\hline Activity & $1.5 \pm 0.6$ & $1.0 \pm 0.2$ & 0.001 \\
\hline Inflammation & $1.7 \pm 0.7$ & $1.1 \pm 0.2$ & 0.001 \\
\hline Atrophy & $1.3 \pm 0.5$ & $1.4 \pm 0.5$ & 0.360 \\
\hline H.pylori density & $1.3 \pm 0.5$ & $1.5 \pm 0.7$ & 0.058 \\
\hline CagA seropositivity $(\mathrm{n}, \%)$ & $8(16 \%)$ & $108(63.5 \%)$ & 0.001 \\
\hline
\end{tabular}

CagA - cytotoxin-associated antigen; H.pylori - Helicobacter pylori; SD - standard deviation. 


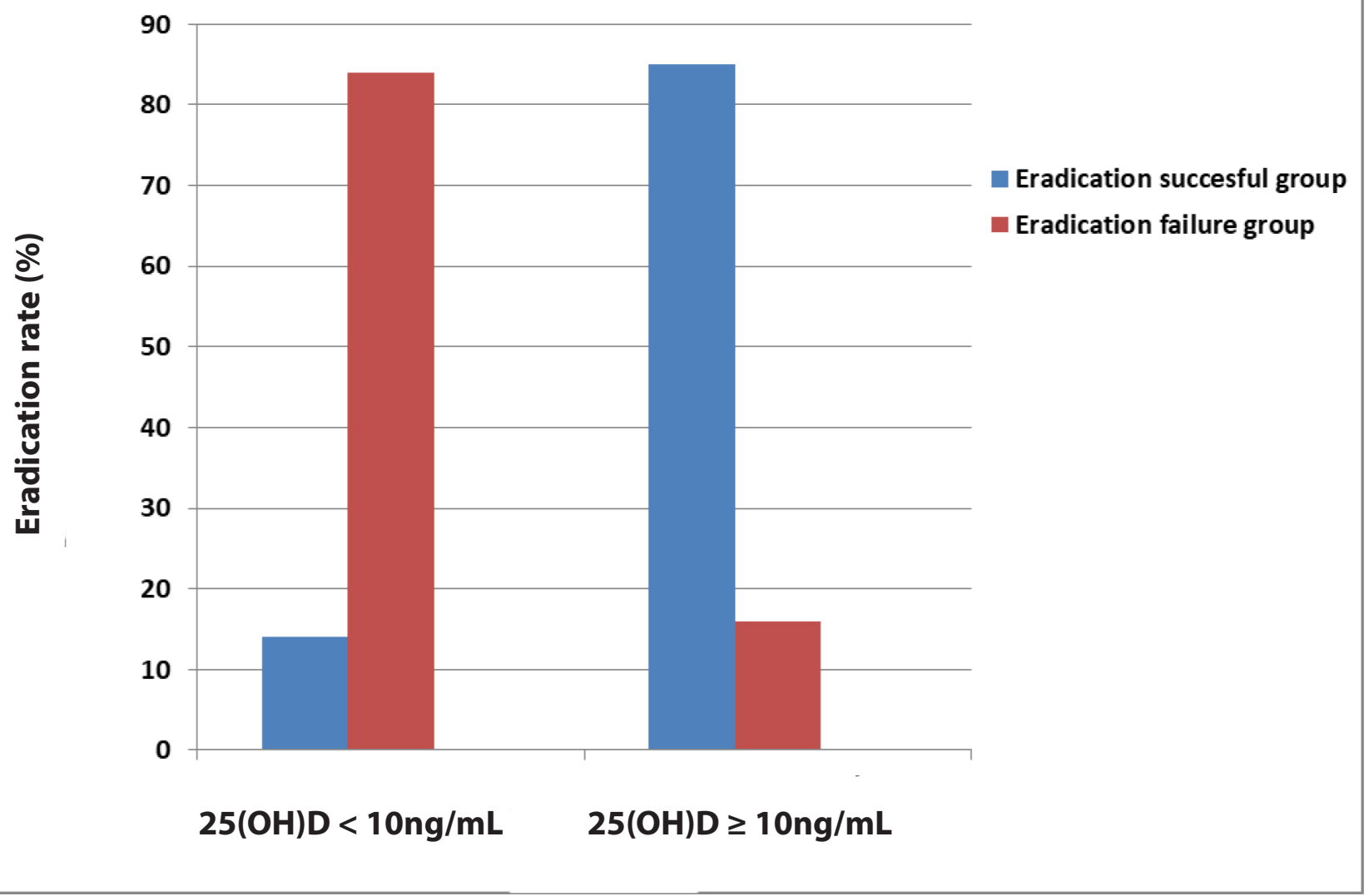

Fig. 1. Comparison of successful and failure rates of H.pylori eradication according to the vitamin 25(OH)D levels

Determining the antibioticresistance of H.pylori strains is the most important factor for achieving effective eradication therapy. Worldwide, antibiotic resistance has been reported at an increasing rate (16.2-60.7\%), particularly to clarithromycin and metronidazole. ${ }^{10}$ Increasing the susceptibility of some antibiotics, another important factor is maintaining a high intragastric $\mathrm{pH}$ for $24 \mathrm{~h}$. Although several studies have shown that standard triple therapies are effective in most patients as a first-line treatment, we treated the patients with a bismuth-containing quadruple eradication therapy, which is recommended as a first-line treatment in regions where clarithromycin resistance is $>15 \% .{ }^{11}$ CagA expression in CagA-positive H.pylori strains is another bacterial factor in H.pylori eradication therapy. Research has shown it to be associated with the host inflammatory response and an increased risk for clinical outcomes. ${ }^{12}$ Van Doorn et al. have shown an association between lower eradication efficacy and H.pylori strains missing the CagA gene, while Scholte et al. did not find this relation. ${ }^{13,14}$ The present study indicated that H.pylori eradication rates were significantly higher in patients infected with CagA-positive strains compared to negative ones (CagA-positive, 63.5\%; CagA-negative, 36.5\%; $\mathrm{p}=0.001$ ). It is possible that CagA-positive strains cause more intense gastric mucosal inflammation, which may play a role in eradication by increasing the blood flow, thus improv- ing the flow of antibiotics. ${ }^{15}$ Recent studies have shown higher H.pylori density by histopathology to be related with complications while indicating a negative correlation with $H$.pylori eradication rates. ${ }^{16,17}$ Our study, however, found no significant difference. It is important to note that both of these studies used the triple therapy. Bacterial density does not seem to negatively affect differing treatment of bismuth + quadruple therapy adapted in our study. Previous studies have reported histopathological findings predicting H.pylori treatment failure. ${ }^{18,19}$ Our study demonstrated that high histological scores of gastritis and activity are effective in determining eradication success. However, there was no significant difference in eradication rates of $H$.pylori according to the severity of atrophy in the antrum. The host immune system has been hypothesized to affect pharmacological treatment in H.pylori eradication. Some authors have found that impaired mucosal immune response may contribute to eradication failure in H.pylori infection. ${ }^{20,21}$ Vitamin D has a long tradition of playing a role in regulating calcium and phosphorus metabolism, but it has also proven effective as a potent immune modulator of the adaptive immune system, stimulating the innate immune response upon infection. ${ }^{22}$ Recent studies have demonstrated the relationship between vitamin D deficiency and infectious diseases. ${ }^{23,24}$ Vitamin D regulates the innate immune system in macrophages against $\mathrm{Myco-}$ 
bacterium tuberculosis through the mechanisms of activated toll-like receptors (TLRs), leading to the induction of antimicrobial peptide cathelicidin that kills the organism. ${ }^{25}$ A recent meta-analysis has found that low serum $25(\mathrm{OH}) \mathrm{D}$ levels are associated with a higher risk of active tuberculosis. ${ }^{26}$ We have evaluated the possible association between vitamin D levels and H.pylori infection.

Our study primarily demonstrates the relationship between H.pylori eradication rates and low vitamin D levels. We found that H.pylori eradication rates were significantly lower in patients with vitamin D deficiency. A potential pathogenic mechanism explaining the observed association between vitamin D status and eradication rates is impairment of the vitamin D signal immune function, which may lead to inadequate immune response. There is limited data demonstrating the relationship between vitamin $\mathrm{D}$ and H.pylori infection. One in vitro study showed the selective antibacterial effect of vitamin D3 decomposition product (VDP1) against H.pylori. ${ }^{27}$ Vitamin D is also known to regulate the expression of antimicrobial peptides - cathelicidin and $\beta$-defensin, which kill the bacteria. Although the effect of cathelicidin has been demonstrated only in macrophages infected with $M$. tuberculosis, antibacterial action against gram-negative and gram-positive bacteria has also been reported. ${ }^{28,29}$ Another antimicrobial peptides $\beta$-defensin, which is secreted in the gastric mucosa after infection by H.pylori, constitutes immune defense against this bacterial pathogen at the mucosal surface. ${ }^{30}$ In a vitamin D-deficient state, the infected macrophage is unable to produce sufficient 1,25- $(\mathrm{OH}) \mathrm{D} 2$ to upregulate the production of cathelicidin and $\beta$-defensin, thus rendering them unable to kill the H.pylori strains.

In this paper, we have demonstrated low eradication success in infected patients with vitamin $\mathrm{D}$ deficiency. Vitamin D deficiency may be a risk factor associated with H.pylori infection treatment failure and may lead to a need for supplementation of vitamin D before H.pylori eradication therapy. More prospectively designed clinical trials considering pre-treatment vitamin $\mathrm{D}$ levels are needed to further evaluate the relationship between vitamin D status and H.pylori infection.

\section{References}

1. Dunn BE, Cohen H, Blaser MJ. Helicobacter pylori. Clin Microbiol Rev. 1997;10(4):720-724.

2. Perez-Perez Gl, Rothenbacher D, Brenner H. Epidemiology of Helicobacter pylori infection. Helicobacter. 2004;9(Suppl 1):1-6.

3. Malfertheiner P, Link A, Selgrad M. Helicobacter pylori: Perspectives and time trends. Nat Rev Gastroenterol Hepatol. 2014;11(10):628-388.

4. Take S, Mizuno M, Ishiki K, et al. The effect of eradicating Helicobacter pylori on the development of gastric cancer in patients with peptic ulcer disease. Am J Gastroenterol. 2005;100:1037-1042.

5. Uotani T, Miftahussurur M, Yamaoka Y. Effect of bacterial and host factors on Helicobacter pylori eradication therapy. Expert Opin Ther Targets. 2015;19(12):1637-1650.

6. Baeke F, Takiishi T, Korf H, Gysemans C, Mathieu C. Vitamin D: Modulator of the immune system. Curr Opin Pharmacol. 2010;10(4):482-496.

7. Hong JY, Kim SY, Chung KS, et al. Association between vitamin D deficiency and tuberculosis in a Korean population. Int J Tuberc Lung Dis. 2014;18(1):73-78.
8. Dixon MF, Genta RM, Yardley JH, Correa P. Classification and grading of gastritis. The updated Sydney system. International Workshop on the Histopathology of Gastritis, Houston 1994. Am J Surg Pathol. 1996;20(10):1161-1181.

9. Lips P. Vitamin D status and nutrition in Europe and Asia. J Steroid Biochem Mol Biol. 2007;103:620-625.

10. Gatta L, Vakil N, Vaira D, Scarpignato C. Global eradication rates for Helicobacter pylori infection: Systematic review and meta-analysis of sequential therapy. BMJ. 2013;347:f4587.

11. Malfertheiner P, Megraud F, O'Morain CA, et al. Management of Helicobacter pylori infection - The Maastricht IV/ Florence Consensus Report. Gut. 2012;61:642-664.

12. Bagheri N, Azadegan-Dehkordi F, Shirzad H, Rafieian-Kopaei M, Rahimian G, Razavi A. The biological functions of IL-17 in different clinical expressions of Helicobacter pylori-infection. Microb Pathog. 2015;81:338.

13. van Doorn LJ, Schneeberger PM, Nouhan N, Plaisier AP, Quint WGV, de Boer WA. Importance of Helicobacter pylori CagA and VacA status for the efficacy of antibiotic treatment. Gut. 2000;46:321-326.

14. Scholte GH, van Doorn LJ, Cats A, et al. Genotyping of Helicobacter pylori in paraffin-embedded gastric biopsy specimens: Relation to histological parameters and effects on therapy. Am J Gastroenterol. 2002;97(7):1687-1695.

15. Maeda S, Yoshida $\mathrm{H}$, Ikenoue $\mathrm{T}$, et al. Structure of cag pathogenicity island in Japanese Helicobacter pylori isolates. Gut. 1999;44(3):336-341.

16. Shah DK, Jain SS, Mohite A, Amarapurkar AD, Contractor QQ, Rathi PM. Effect of $H$. pylori density by histopathology on its complications and eradication therapy. Trop Gastroenterol. 2015;36(2):101-106.

17. Onal IK, Gokcan H, Benzer E, Bilir G, Oztas E. What is the impact of Helicobacter pylori density on the success of eradication therapy: A clinico-histopathological study. Clin Res Hepatol Gastroenterol. 2013;37(6):642-646.

18. Zambon CF, Fasolo $M$, Basso $D$, et al. Clarithromycin resistance, tumor necrosis factor alpha gene polymorphism and mucosal inflammation affect $H$. pylori eradication success. J Gastrointest Surg. 2007;11(11):1506-1514.

19. Kamada T, Haruma K, Komoto K, et al. Effect of smoking and histological gastritis severity on the rate of $\mathrm{H}$. pylori eradication with omeprazole, amoxicillin, and clarithromycin. Helicobacter. 1999;4(3):204-210.

20. Borody T, Ren Z, Pang G, Clancy R. Impaired host immunity contributes to Helicobacter pylori eradication failure. Am J Gastroenterol. 2002;97:3032-3037.

21. Clancy R, Borody T, Ren Z, Pang G. Can the response to eradication therapy in Helicobacter pylori infection be predicted? Can J Gastroenterol. 2003;17(Suppl B):58B-61B.

22. Penna G, Roncari A, Amuchastegui $S$, et al. Expression of the inhibitory receptor ITL3 on dendritic cells is dispensable for induction of CD4pFoxp3p regulatory T cells by 1,25-dihy-droxyvitamin D3. Blood. 2005;106:3490-3497.

23. Sahay T, Ananthakrishnan AN. Vitamin D deficiency is associated with community-acquired clostridium difficile infection: A casecontrol study. BMC Infect Dis. 2014;14:661.

24. Grant WB. Variations in vitamin D production could possibly explain the seasonality of childhood respiratory infections in Hawaii. Pediatr Infect Dis J. 2008;27:853.

25. Liu PT, Stenger S, Li H, et al. Toll-like receptor triggering of a vitamin D-mediated human antimicrobial response. Science. 2006;311(5768):1770-1773.

26. Nnoaham KE, Clarke A. Low serum vitamin D levels and tuberculosis: A systematic review and meta-analysis. Int J Epidemiol. 2008;37(1):113-119.

27. Hosoda K, Shimomura H, Wanibuchi K, et al. Identification and characterization of a vitamin $D_{3}$ decomposition product bactericidal against Helicobacter pylori. Sci Rep. 2015;5:8860.

28. Ramanathan B, Davis EG, Ross CR, Blecha F. Cathelicidins: Microbicidal activity, mechanisms of action, and roles in innate immunity. Microbes Infect. 2002;4:361-372.

29. Wang TT, Nestel FP, Bourdeau V, et al. Cutting edge: 1,25-dihydroxyvitamin D3 is a direct inducer of antimicrobial peptide gene expression. J Immunol. 2004;173(5):2909-2912.

30. Wehkamp J, Schauber J, Stange EF. Defensins and cathelicidins in gastrointestinal infections. Curr Opin Gastroenterol. 2007;23:32-38. 